\title{
Effect of cyclical intermittent etidronate therapy on circulating osteoprotegerin levels in patients with rheumatoid arthritis
}

\author{
Heikki Valleala ${ }^{1}$, Jami Mandelin ${ }^{2}$, Leena Laasonen ${ }^{3}$, Marja-Kaisa Koivula ${ }^{4}$, Juha Risteli ${ }^{4,5}$ and \\ Yrjö T Konttinen ${ }^{1,2,6}$ \\ ${ }^{1}$ Department of Medicine, Helsinki University Central Hospital, Helsinki, Finland, ${ }^{2}$ Biomedicum/Anatomy, University of Helsinki, Finland, \\ ${ }^{3}$ Department of Radiology, Helsinki University Central Hospital, Helsinki, Finland, ${ }^{4}$ Department of Clinical Chemistry, University of Oulu, Oulu, Finland, \\ ${ }^{5}$ Kuopio University Hospital, Kuopio, Finland and ${ }^{6}$ ORTON Research Institute and the Orthopaedic Hospital of the Invalid Foundation, Helsinki, Finland
}

(Correspondence should be addressed to H Valleala, Department of Medicine, Helsinki University Central Hospital, Kasarmikatu 11-13,

FIN-00130 Helsinki, Finland; Email: heikki.valleala@hus.fi)

\begin{abstract}
Objective: To evaluate the role of serum osteoprotegerin (OPG) as a biochemical marker for disease activity assessment and drug monitoring in patients with rheumatoid arthritis (RA) treated with cyclical etidronate.

Design: Forty patients ( 35 women and 5 men) with RA of $<5$ years duration were randomized to receive intermittent cyclical etidronate therapy in conjunction with anti-rheumatic therapy or anti-rheumatic therapy alone (without etidronate) in a 2-year, open-label protocol.

Methods: Radiographs of hands and feet and serum samples for the determination of OPG, amino terminal propeptide (PINP), cross-linked C-telopeptide (ICTP) and amino terminal telopeptid of type I collagen were obtained at baseline and at 24 months.

Results: Etidronate treatment had no effect on circulating OPG levels, although the significant decline in PINP and ICTP $(P=0.001$ and $P=0.04$ respectively) reflected the efficacy of the anti-resorptive therapy. At baseline and at study termination, serum OPG correlated significantly with age $(r=0.45$; $P=0.003$ and $r=0.56 ; P=0.0002$ respectively). OPG was not related to biochemical markers of bone metabolism, indices of disease activity or radiographic disease progression. At baseline, the mean serum OPG was higher in patients receiving $5-10 \mathrm{mg} /$ day prednisone $(82.8 \pm 4.0 \mathrm{pg} / \mathrm{ml}$, $n=16)$ compared with those receiving $<5 \mathrm{mg} /$ day or with no prednisone $(69.7 \pm 4.7 \mathrm{pg} / \mathrm{ml}$, $n=23)(P=0.05)$.

Conclusions: Our results suggested that serum OPG measurement, perhaps because of the complexity of the regulation of the OPG, may be difficult to utilize in the evaluation of anti-resorptive therapy. Moreover, low dose corticosteroid-associated osteoporosis is probably not mediated by inhibition of OPG.
\end{abstract}

European Journal of Endocrinology 148 527-530

\section{Introduction}

Osteoprotegerin (OPG) is a soluble decoy receptor that binds to and inactivates receptor activator of nuclear factor- $\mathrm{kB}$ (RANKL), a factor essential for osteoclast development and activity. Apart from bone metabolism, the RANKL/OPG system plays an important role in the development and function of the immune system and in vascular biology. OPG is produced by a variety of tissues, including the cardiovascular system, lungs, kidneys and bones. The expression and production of OPG is modulated by many osteotropic agents, including cytokines such as tumor necrosis factor (TNF)- $\alpha$ and interleukin-1, and steroid and peptide hormones such as $17 \beta$-estradiol, 1,25-dihydroxyvitamin D, glucocorticoids and parathyroid hormone (1).

While OPG deficiency has been found to be associated with osteoporosis in various animal models (1), the administration of OPG inhibits bone resorption in ovariectomized rats (2) and in postmenopausal women (3). Abnormalities in the RANKL/OPG system have been implicated also in the pathogenesis of other metabolic bone diseases including rheumatoid arthritis (RA) (1). In the rat adjuvant-arthritis model, administration of OPG leads to protection from destruction during the course of arthritis (4).

These findings suggest that OPG could have an application as a potent anti-resorptive drug. However, the role of serum OPG measurement as a biochemical marker for disease activity assessment and drug monitoring has not yet been fully elucidated (5). To evaluate the response of serum OPG to anti-resorptive therapy and the relation of serum OPG to radiographic disease progression, we analyzed the serum for OPG in RA patients from our 2-year trial with cyclical etidronate (6). 


\section{Patients and methods}

\section{Patients}

We analyzed serum for OPG from our previous study assessing the effects of cyclical etidronate therapy on biochemical markers of bone metabolism and progression of radiologic joint damage in 40 RA patients of $<5$ years duration (6). The study was approved by the local Medical Ethical Committees. All 40 participants completed the study except for one patient in the etidronate group who died of pneumonia during the second year of the study and was not included in the analyses except for the baseline correlation assessments. Baseline serum sample for bone biochemistry was not obtained from one patient in the etidronate-treated group and she was excluded from those evaluations where these values were needed. Table 1 shows the characteristics of the study population. There were no statistically significant differences between the groups.

\section{Study protocol}

This has been described in detail in our previous report (6). Briefly, upon entry to the study, the patients were randomly allocated to one of two treatment groups. The etidronate-treated group $(n=20)$ received intermittent cyclical oral etidronate disodium (a gift from Roche, Espoo, Finland) at $400 \mathrm{mg}$ daily for 2 weeks every $12-14$ weeks (eight cycles in total) in conjunction with anti-rheumatic therapy. The control group $(n=20)$ received only anti-rheumatic therapy. Changes to the concomitant therapy with anti-rheumatic drugs and/or oral steroids could be made whenever considered appropriate throughout the study period in both groups.

\section{Methods}

The following disease parameters were measured: erythrocyte sedimentation rate ((ESR) Westergren method), C-reactive score (CRP) level, number of

Table 1 Patient characteristics at baseline. Values are means \pm S.E.M

\begin{tabular}{lcc}
\hline & $\begin{array}{c}\text { Etidronate group } \\
(n=19)\end{array}$ & $\begin{array}{c}\text { Control group } \\
(n=20)\end{array}$ \\
\hline Age (years) & $48.5 \pm 2.4$ & $52.6 \pm 3.5$ \\
(range) & $(22-66)$ & $(26-78)$ \\
Males/females & $2 / 17$ & $2 / 18$ \\
Menopausal status (yes/no) & $12 / 5$ & $11 / 7$ \\
HRT/postmenopausal women & $6 / 12$ & $6 / 11$ \\
Disease duration (months) & $34.9 \pm 3.5$ & $36.2 \pm 3.1$ \\
DAS28 & $4.0 \pm 0.3$ & $3.6 \pm 0.3$ \\
CRP (mg/l) & $26.1 \pm 9.0$ & $25.1 \pm 4.5$ \\
Total radiographic score & $18.0 \pm 5.2$ & $16.5 \pm 3.3$ \\
Glucocorticoid therapy (\%) & $9(47)$ & $12(60)$ \\
\hline
\end{tabular}

HRT, hormone replacement therapy. tender and swollen joints (28 joint count), patient overall assessment of current disease activity on a visual analogue scale of $0-100 \mathrm{~mm}$, and modified disease activity score (DAS28) using 28 joint counts (7). Serum samples for bone biochemistry assessments were collected at baseline and 24 months and stored at $-20^{\circ} \mathrm{C}$. OPG concentrations were determined using a commercial sandwich enzyme immunoassay provided by Immunodiagnostik (Bensheim, Germany) (8). The lower limit of detection of this assay is $3 \mathrm{pg} / \mathrm{ml}$. According to the manufacturer both the intra- and interassay coefficients $(n=16)$ of variation were less than $10 \%$. Radioimmunologic assays used to measure serum N-propeptide of type I procollagen (PINP) and cross-linked C-telopeptide of type I collagen (ICTP) (Orion Diagnostica, Espoo, Finland) (9, 10) and the enzyme-linked immunosorbent method (Ostex International, Seattle, WA, USA) for the measurement of serum N-telopeptide of type I collagen (NTx) (11) have been described elsewhere. According to the manufacturers, the intra- and interassay coefficients of variation were less than $11 \%$. All determinations were done in duplicates. Plain posteroanterior radiographs of hands and feet were obtained at baseline and at 24 months and were scored in a chronological order according to van der Heijde's modification of Sharp's method (12) by one experienced reader (L L) who was unaware of the treatment assignments.

\section{Statistical analysis}

The data are presented as means \pm S.E.M. if not otherwise stated. The changes in response variables from baseline to 24 months were compared between treatment groups using the Mann-Whitney $U$ test. Categorical data were compared by chi-square test. The relation between variables was measured by estimating the Pearson product moment correlation coefficient or by using Spearman's rank correlation coefficient. The significance level was set at $P<0.05$. Statistical analysis was done with SPSS-9.0 software.

\section{Results}

The effects of cyclical etidronate treatment on various disease variables have been reported previously (6). Briefly, the mean Sharp score increased significantly in both treatment groups, by $5.7 \pm 1.5$ in the etidronate-treated group and by $6.9 \pm 1.7$ in the control group. Etidronate had no effect on clinical or laboratory parameters of disease activity, but caused a significant decline in both PINP and ICTP (Table 2). The groups did not differ for the change in serum NTx.

At baseline and at study termination (Fig. 1), serum OPG correlated significantly with age $(r=0.45$; $P=0.003$ and $r=0.56 ; P=0.0002$ respectively), but not with biochemical markers of bone metabolism, 
Table 2 Biochemical serum indices of bone metabolism at baseline and changes at 24 months in the etidronate-treated group $(n=18)$ and the control group $(n=20)$.

\begin{tabular}{lccc}
\hline Variable & Baseline & Change at 24 months & $\boldsymbol{P}$ \\
\hline PINP $(\mu \mathrm{g} / \mathrm{l})$ & & & 0.001 \\
$\quad$ Etidronate & $36.3 \pm 4.5$ & $-9.0 \pm 3.2$ & \\
$\quad$ Control & $35.1 \pm 3.4$ & $15.4 \pm 6.1$ & \\
ICTP $(\mu \mathrm{g} / \mathrm{l})$ & & & 0.04 \\
$\quad$ Etidronate & $3.3 \pm 0.4$ & $-0.5 \pm 0.2$ & \\
$\quad$ Control & $3.3 \pm 0.4$ & $0.6 \pm 0.6$ & \\
OPG $(\mathrm{pg} / \mathrm{ml})$ & & & 0.91 \\
$\quad$ Etidronate & $74.3 \pm 5.3$ & $3.7 \pm 3.7$ & \\
Control & $75.9 \pm 4.6$ & $2.3 \pm 3.1$ & \\
NTx (nmol BCE/l) & & & \\
$\quad$ Etidronate & $15.2 \pm 1.0$ & $-0.7 \pm 0.6$ & \\
Control & $15.9 \pm 1.4$ & $1.5 \pm 1.4$ & \\
\hline
\end{tabular}

$\mathrm{BCE}$, bone collagen equivalent.

PINP: reference range, men $20-76 \mu \mathrm{g} /$; women $19-84 \mu \mathrm{g} / \mathrm{l}$.

ICTP: reference range, $1.6-4.6 \mu \mathrm{g} / \mathrm{ml}$.

NTx: reference range, men $8.1-24.8 \mathrm{nmol} \mathrm{BCE} / \mathrm{l}$; women $7.7-19.3 \mathrm{nmol}$ $\mathrm{BCE} / \mathrm{l}$.

indices of disease activity or radiological scores. Etidronate had no effect on circulating OPG levels (Table 2). The change in serum OPG was not related to the change in biochemical markers of bone metabolism or progression of radiologic joint damage during the 2-year study (Table 3). At baseline, the mean serum OPG was higher in patients receiving $5-10 \mathrm{mg} /$ day prednisone $(82.8 \pm 4.0 \mathrm{pg} / \mathrm{ml}, n=16)$

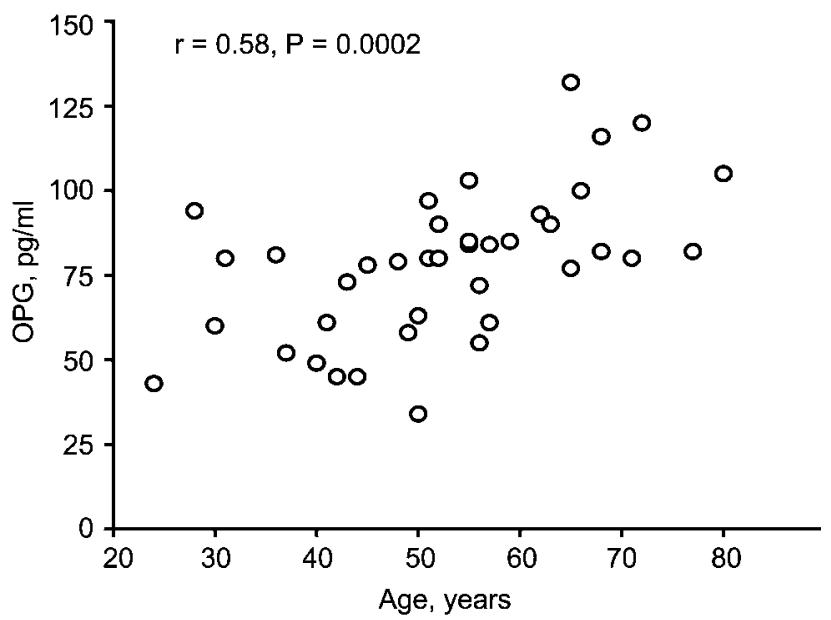

Figure 1 Correlation between serum levels of OPG and age in 39 RA patients. compared with those receiving $<5 \mathrm{mg}$ /day or with no prednisone $(69.7 \pm 4.7 \mathrm{pg} / \mathrm{ml}, n=23)(P=0.05)$. At baseline, serum OPG correlated positively with prednisone dose (Spearman's $r=0.36, P=0.02$ ).

\section{Discussion}

In a study from Japan (13) conducted in 186 postmenopausal women, OPG serum levels correlated positively with biochemical markers of bone turnover and negatively with bone mineral density (BMD). Although these findings were not confirmed by Szulc et al. (8) in a cohort of 252 healthy men, a generally accepted hypothesis is that OPG levels may increase with increases in bone turnover, possibly as a compensatory mechanism (14). Consequently, etidronate with its demonstrated efficacy in the treatment of postmenopausal (15) as well as in steroid-induced (16) osteoporosis could have been expected to decrease serum OPG. In fact, serum OPG slightly increased in the etidronate-treated patients, despite the probable inhibition of bone resorption in this group as suggested by the significant decline in serum ICTP and PINP (17). However, in vitro bisphosphonates increase OPG expression in human osteoblasts (18), and therefore a direct effect of etidronate on OPG production in bone tissue cannot be excluded.

Recently Ziolkowska et al. (19) reported normalization of elevated serum OPG levels in RA patients after treatment with anti-TNF $\alpha$ therapy but, similar to our results, they did not find a correlation between clinical disease activity (DAS28) and serum OPG. Here we have described a lack of correlation between serum OPG and radiographic disease progression. In our cohort of RA patients, age was the only parameter that was significantly related to serum OPG. The age-related increase of OPG found in most previous studies possibly represents a compensatory mechanism against age-dependent bone loss. Decreased clearance of OPG with age, however, has been proposed as an alternative explanation (14) for this finding.

Our study had some potential limitations. The number of patients was small and the study did not include serial BMD measurements. Determination of RANKL serum levels might have added to the information from this trial. The RANKL:OPG ratio might show greater utility for the assessment of the efficacy of anti-resorptive therapy than serum OPG alone.

Table 3 Correlation matrix showing relationships between changes in serum OPG and changes in the levels of markers of collagen metabolism and radiologic scores during a 2-year study in the total study population $(n=38)$.

\begin{tabular}{|c|c|c|c|c|c|c|}
\hline Parameter & Total SHS & Erosion score & JSN score & ICTP & NTx & PINP \\
\hline OPG & $\begin{array}{l}r=0.02 \\
P=0.90\end{array}$ & $\begin{array}{l}r=0.03 \\
P=0.85\end{array}$ & $\begin{array}{l}r_{s}=0.01 \\
P=0.93\end{array}$ & $\begin{array}{l}r_{\mathrm{s}}=0.004 \\
P=0.98\end{array}$ & $\begin{array}{l}r=-0.06 \\
P=0.72\end{array}$ & $\begin{array}{l}r=-0.08 \\
P=0.64\end{array}$ \\
\hline
\end{tabular}

Pearson product moment correlation coefficient $(r)$ was calculated for normally distributed parameters and Spearman's rank order correlation $\left(r_{s}\right)$ for non-normally distributed data (ICTP, JSN).

SHS, Sharp score as modified by van der Heijde (12); JSN score, joint space narrowing score. 
Glucocorticoids inhibit OPG production in human osteoblastic linage cells (20) and Sasaki et al. (21) reported that high-dose systemic glucocorticoid therapy with a mean initial dose of $43.8 \mathrm{mg} /$ day led to decreased OPG serum levels. OPG levels remained suppressed after 6 months of therapy when the mean daily prednisone dose had been lowered to $16.5 \mathrm{mg}$. These findings are in contrast to our results and the observation that serum OPG is elevated in patients with Cushing's syndrome (22). Possibly prednisone doses higher than $10 \mathrm{mg}$ /day are needed to inhibit OPG production in vivo. At lower doses, other mechanisms lead to negative balance between bone formation and resorption (23) and the elevated OPG levels may represent an insufficient counter-regulatory mechanism to prevent bone loss.

The central role of the RANKL/OPG system in the regulation of bone cell biology is well established. Our results suggest, however, that serum OPG measurement may be difficult to utilize in the evaluation of antiresorptive therapy. This is probably due to the ubiquitous origin of OPG and the complexity of its regulation.

\section{Acknowledgements}

The authors wish to thank Svetlana Solovieva for advice concerning the statistical analysis of the data. This study was financially supported by Sigrid Juselius Foundation, Finska Läkaresällskapet, Invalid Foundation, and Helsinki University Central Hospital Research Funds.

\section{References}

1 Hofbauer LC \& Heufelder AE. Role of receptor activator of nuclear factor-kappaB ligand and osteoprotegerin in bone cell biology. Journal of Molecular Medicine 2001 79 243-253.

2 Simonet WS, Lacey DL, Dunstan CR, Kelley M, Chang MS, Luthy R et al. Osteoprotegerin: a novel secreted protein involved in the regulation of bone density. Cell $1997 \mathbf{8 9} 309-319$.

3 Bekker PJ, Holloway D, Nakanishi A, Arrighi M, Leese PT \& Dunstan CR. The effect of a single dose of osteoprotegerin in postmenopausal women. Journal of Bone and Mineral Research 2001 $16348-360$.

4 Kong YY, Feige U, Sarosi I, Bolon B, Tafuri A, Morony S et al. Activated cells regulate bone loss and joint destruction in adjuvant arthritis through osteoprotegerin ligand. Nature $1999 \mathbf{4 0 2}$ 304-309.

5 Hofbauer LC \& Schoppet M. Serum measurement of osteoprotegerin - clinical relevance and potential applications. European Journal of Endocrinology $2001 \mathbf{1 4 5} 681-683$.

6 Valleala H, Laasonen L, Koivula M-K, Mandelin J, Friman C, Juha Risteli et al. Two year, randomized, controlled trial of rheumatoid arthritis with etidronate: changes in serum aminoterminal telopeptides correlate with the radiographic progression of the disease. Journal of Rheumatology $2003 \mathbf{3 0}$ 468-473.

7 van Gestel AM, Haagsma CJ \& van Riel PLCM. Validation of rheumatoid arthritis improvement criteria that include simplified joint counts. Arthritis and Rheumatism 199841 1845-1850.

8 Szulc P, Hofbauer LC, Heufelder AE, Roth S \& Delmas PD. Osteoprotegerin serum levels in men: correlation with age, estrogen, and testosterone status. Journal of Clinical Endocrinology and Metabolism $2001863162-3165$.

9 Melkko J, Kauppila S, Niemi S, Risteli L, Haukipuro K, Jukkola A et al. Immunoassay for intact amino-terminal propeptide of human type I procollagen. Clinical Chemistry 199642 947-954.

10 Risteli J, Elomaa I, Niemi S, Novamo A \& Risteli L. Radioimmunoassay for the pyridinoline cross-linked carboxy-terminal telopeptide of type I collagen: a new serum marker of bone collagen degradation. Clinical Chemistry 199339 635-640.

11 Clemens JD, Herrick MV, Singer FR \& Eyre DR. Evidence that serum NTx (collagen-type I N-telopeptides) can act as an immunochemical marker of bone resorption. Clinical Chemistry $1997432058-2063$.

12 van der Heijde D. How to read radiographs according to the Sharp/van der Heijde method. Journal of Rheumatology 199926 $743-745$.

13 Yano K, Tsuda E, Washida N, Kobayashi F, Goto M, Harada A et al. Immunological characterization of circulating osteoprotegerin/ osteoclastogenesis inhibitory factor: increased serum concentrations in postmenopausal women with osteoporosis. Journal of Bone and Mineral Research 199914 518-527.

14 Khosla S, Arrighi HM, Melton LJ III, Atkinson EJ, O’Fallon WM, Dunstan C et al. Correlates of osteoprotegerin levels in women and men. Osteoporos International 200213 394-399.

15 Storm T, Thamsborg G, Steiniche T, Genant HK \& Sorensen OH. Effect of intermittent cyclical etidronate therapy on bone mass and fracture rate in women with postmenopausal osteoporosis. New England Journal of Medicine 1990322 1265-1271.

16 Adachi JD, Bensen WG, Brown J. Hanley D, Hodsman A, Josse R et al. Intermittent etidronate therapy to prevent corticosteroidinduced osteoporosis. New England Journal of Medicine 1997 $337382-387$

17 Saarto T, Blomqvist C, Risteli J, Risteli L, Sarna S \& Elomaa I. Aminoterminal propeptide of type I procollagen (PINP) correlates to bone loss and predicts the efficacy of antiresorptive therapy in pre- and post-menopausal non-metastatic breast cancer patients. British Journal of Cancer $1998 \mathbf{7 8} 240-245$.

18 Viereck V, Emons G, Lauck V, Frosch KH, Blaschke S \& Grundker C. Bisphosphonates pamidronate and zoledronic acid stimulate osteoprotegerin production by primary human osteoblasts. Biochemical and Biophysical Research Communications 2002291 $680-686$.

19 Ziolkowska M, Kurowska M, Radzikowska A, Luszczykiewicz G, Wiland P, Dziewczopolski W et al. High levels of osteoprotegerin and soluble receptor activator of nuclear factor $B$ ligand in serum of rheumatoid arthritis patients and their normalization after anti-tumor necrosis factor treatment. Arthritis and Rheumatism 200246 1744-1753.

20 Hofbauer LC, Gori F, Riggs BL, Lacey DL, Dunstan CR \& Spelsberg TC. Stimulation of osteoprotegerin ligand and inhibition of osteoprotegerin production by glucocorticoids in human osteoblastic lineage cells: potential paracrine mechanisms of glucocorticoid-induced osteoporosis. Endocrinology $1999 \quad 140$ $4382-4389$.

21 Sasaki N, Kusano E, Ando Y, Nemoto J, Iimura O \& Ito C. Changes in osteoprotegerin and markers of bone metabolism during glucocorticoid treatment in patients with chronic glomerulonephritis. Bone 200230 853-858.

22 Ueland T, Bollerslev J, Godang K, Muller F, Froland SS \& Aukrust P. Increased serum osteoprotegerin in disorders characterized by persistent immune activation or glucocorticoid excess possible role in bone homeostasis. European Journal of Endocrinology 2001145 685-690.

23 Dempster DW. Bone histomorphometry in glucocorticoid-induced osteoporosis. Journal of Bone and Mineral Research 19894 137-141.

Received 25 November 2002

Accepted 6 February 2003 